\title{
Effects of Attrition on Microstructure of Electroformed Nickel
}

\author{
Furong Zhang ${ }^{1, \mathrm{a}}$, Yong Zhang ${ }^{1,2, \mathrm{~b}^{*}}$, Xueyu $\mathrm{Li}^{1, \mathrm{c}}$ \\ ${ }^{1}$ Department of Mechanical Engineering, Shazhou Institute of Technology,Zhangjiagang 215600, \\ China; \\ ${ }^{2}$ College of Mechanical and Electrical Engineering, Nanjing University of Aeronautics and \\ Astronautics, Nanjing 210016, China \\ azfrghl@163.com, by6982@163.com, 635578117@qq.com
}

Key words:electroforming, friction, microstructure, nickel

Abstract:The nickel deposits of different microstructures were obtained by electroforming with abrasive-assisted, .The effects of friction strength on the surface morphology and the microstructures of the deposits were studied. The results indicate that the deposits with homogeneous microstructures were obtained with the horizontal cathode, during the abrasive-assisted electroforming process of nickel. The surface smoothness was improved and the nickel crystal grain was refined with the increasing linear velocity. The nickel deposits could be obtained with a wide range of microstructures at different speed of the rotating cathode, which the grain size was in the range from $100 \mathrm{~nm}$ to $600 \mathrm{~nm}$. The difference value of growth rate of the various crystal faces is getting smaller with the increasing velocity of the cathode.

\section{Introduction}

Nickel is one of the main metals that can be used in electroforming, and it has good mechanical properties and corrosion resistance. Now nickel electroforming has been employed in fabricating precision dies, rocket engine thrust chamber, shaped charge liner, and other special structure parts[1-4]. However, there are some drawbacks in the traditional electroforming process, such as pinholes, pits and nodules. As deposits grow progressively thicker, the defects on the surface will become worse. To improve the quality and properties of the deposits, many additives are commonly used in the electrolyte for nickel electroforming. However, it is relatively difficult to control the electrolyte with additives during electroforming, because most additives tend to be consumed during electroforming. Furthermore, many brighteners tend to be absorbed on the cathode, which may affect the structure and reduce the properties of deposits[5-9]. The experiment shows that by simultaneous electroforming and polishing process can improve the surface morphology of electroforming layers[10].

In this paper, simultaneous polishing of dynamical hard particles was employed to the nickel electroforming process to overcome the drawbacks above mentioned. The nickel deposits were electroformed without any additives and their microstructure were examined.

\section{Experimental}

Fig.1 illustrates the schematic diagram of the experimental apparatus. The system consists of power supply, cathode unit, anode basket, heater with temperature control equipment and an electrolyte circulating system. The electrolyte compositions in the solution were listed in Table.1. Nickel deposition was controlled at $\mathrm{pH}=4$ in the electrolyte. 
Table.1 Bath composition of Ni electrolyte

\begin{tabular}{|c|c|}
\hline Bath compositions & standard composition \\
\hline $\mathrm{Ni}\left(\mathrm{NH}_{2} \mathrm{SO}_{3}\right)_{2} \cdot 6 \mathrm{H}_{2} \mathrm{O}$ & $400 \mathrm{~g} / 1$ \\
\hline $\mathrm{H}_{3} \mathrm{BO}_{3}$ & $30 \mathrm{~g} / 1$ \\
\hline $\mathrm{NiCl}_{2}$ & $15 \mathrm{~g} / 1$ \\
\hline
\end{tabular}

All solutions were prepared by freshly distilled water. No sulfur-containing Nickel beads were used as the anode. A stainless cylinder mandrel was used as the cathode, and the deposit area was $\varnothing 48 \mathrm{~mm} \times 80 \mathrm{~mm}$. Ceramic beads with diameter of $\varnothing 1-2 \mathrm{~mm}$ were chosen as the hard particles. The current density was held constant at $4 \mathrm{~A} / \mathrm{dm} 2$ while temperature was $43^{\circ} \mathrm{C}$. Before deposition, the mandrel was mechanically polished with 1000-mesh emery papers, rinsed with distilled water. At the end of the process, the cathode was immediately withdrawn, washed with distilled water, dried and then subjected to further characterization measurements.

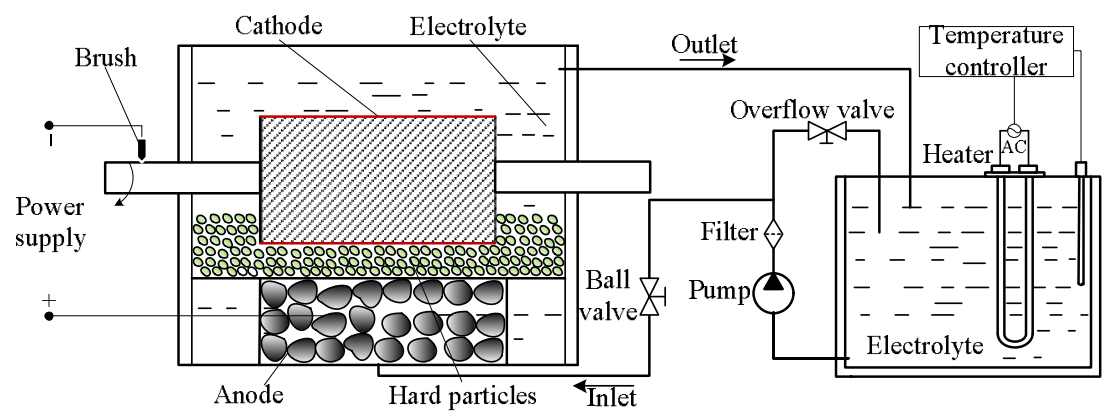

Fig.1 Schematic diagram of experimental apparatus

The cathode mandrel was connected to an motor, the speed of the cathode was varied from 0.0025 to $0.08 \mathrm{~m} / \mathrm{s}$ at a fixed current density of $4 \mathrm{~A} / \mathrm{dm} 2$ and a fixed temperature of $43^{\circ} \mathrm{C}$. All thickness was controlled at about $10 \mu \mathrm{m}$, The surface morphology of the deposits was examined by a LEO-1530VP FEG-SEM. The crystal grain size of the sample electroformed was measured by a JEM-2000EX transmission electron microscope (TEM) at an operating voltage of $160 \mathrm{KV}$. The structure of the samples was measured by a BRUKER D8 ADVANCE X-ray diffraction (XRD) using $\mathrm{Cu} \mathrm{K \alpha}$ radiation. Preferential orientation of the samples was characterized by the orientation index (M) for each plane (hkl).

\section{Results and discussions}

Fig. 2 shows the surface morphology of four typical nickel deposits. As can be seen from the graph, when the linear velocities of cathode was between $0.0025 \mathrm{~m} / \mathrm{s}$ to $0.08 \mathrm{~m} / \mathrm{s}$, the grain size of nickel deposits is gradually decreased with the increasing of linear velocity of cathode. As shown in Fig.2, when the linear velocities of cathode are below $0.02 \mathrm{~m} / \mathrm{s}$, the grain size of nickel deposits is coarse, and when the linear velocities of cathode increased to $0.08 \mathrm{~m} / \mathrm{s}$, the grain size of nickel deposit is obviously refined, and the nickel deposit has obvious traces of friction.

The above results indicate that hard particles can polish the surface of the deposits, sweep off the nodules during electroforming and have a role in grain refinement. When speeding up the velocity of cathode, the polishing effect of hard particles can be strengthened. By observation on the all nickel deposits, we found that the grain size is the same on different parts of the same deposits, indicating that the uniformity of the nickel deposits is very well. 

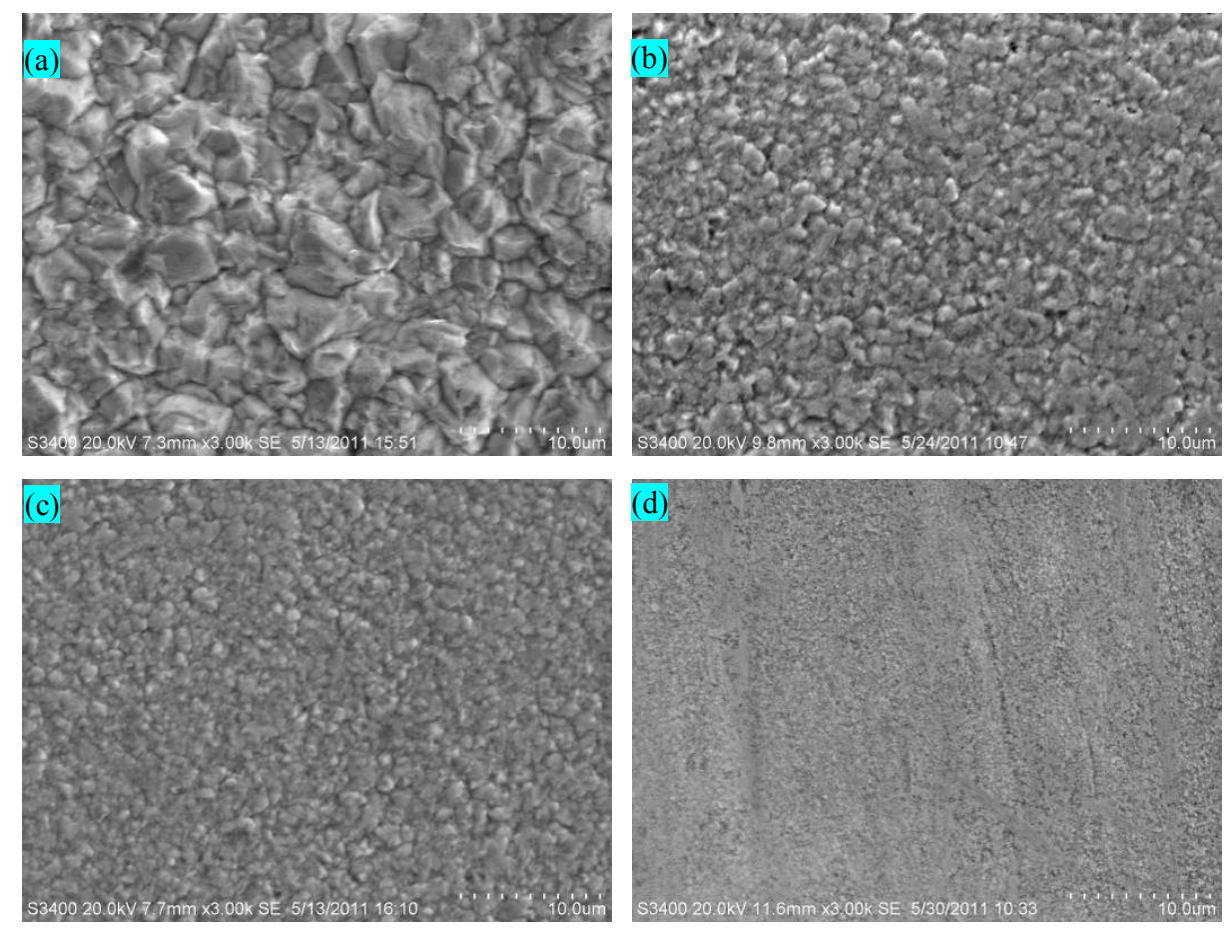

Fig.2 SEM morphology of nickel deposits under different velocities (a) $0.0025 \mathrm{~m} / \mathrm{s} ;($ b) $0.01 \mathrm{~m} / \mathrm{s} ;(c) 0.02 \mathrm{~m} / \mathrm{s} ;(d) 0.08 \mathrm{~m} / \mathrm{s}$

Fig.3 shows the TEM micrograph of four nickel deposits. As can be seen from the graph, the grain size of nickel deposits is gradually decreased with the increasing of linear velocity of cathode. As shown in Fig.2(a), when the linear velocity of cathode is $0.0025 \mathrm{~m} / \mathrm{s}$, the grain size of nickel deposits is greater than $500 \mathrm{~nm}$, and when the linear velocity of cathode increased to $0.08 \mathrm{~m} / \mathrm{s}$, the grain size of nickel deposit is about $100 \mathrm{~nm}$. The above results also indicate that hard particles have a role in grain refinement. When speeding up the velocity of cathode, the polishing effect of hard particles can be strengthened.
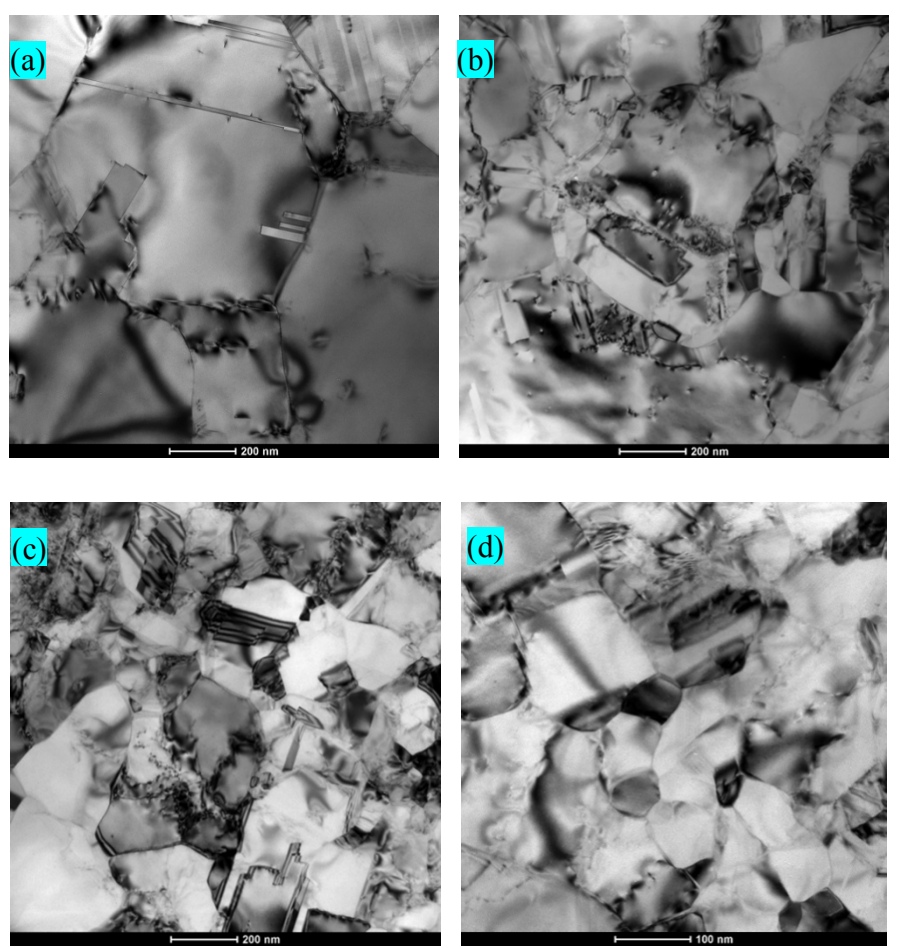

Fig.3 TEM morphology of nickel deposits under different velocities (a) $0.0025 \mathrm{~m} / \mathrm{s} ;($ b) $0.01 \mathrm{~m} / \mathrm{s} ;$ (c) $0.02 \mathrm{~m} / \mathrm{s} ;(d) 0.08 \mathrm{~m} / \mathrm{s}$ 
XRD patterns are shown in Fig.4. Fig.4 (a) is the XRD pattern of nickel deposit electroformed from the bath without hard particles. Fig.5 (b) to Fig.5 (e) are XRD patterns of nickel deposits electroformed under different linear velocities of cathode.
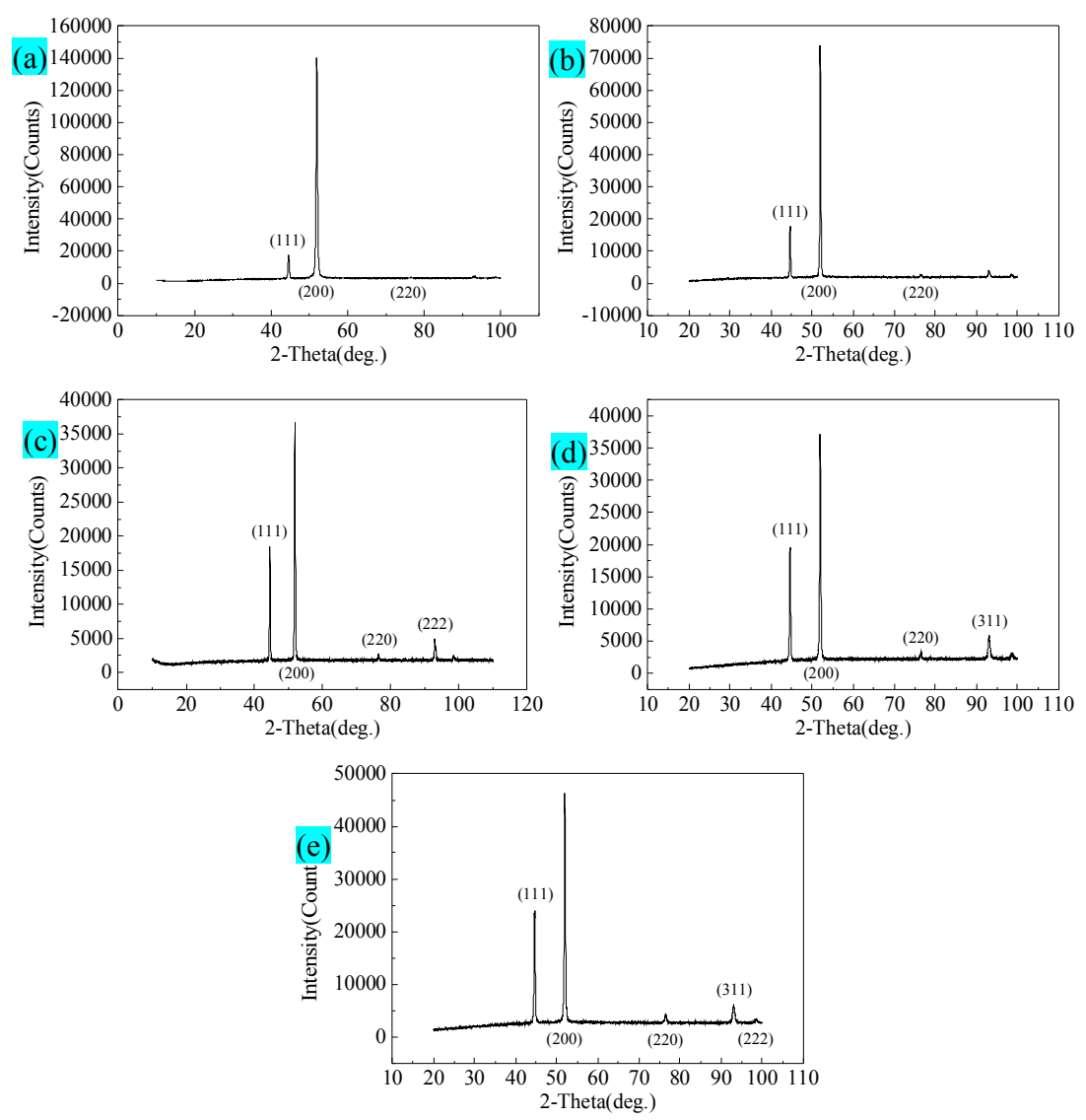

Fig.4 The XRD patterns of Nickel deposits

(a)traditional electroforming;(b) $0.0025 \mathrm{~m} / \mathrm{s} ;(\mathrm{c}) 0.01 \mathrm{~m} / \mathrm{s} ;(\mathrm{d}) 0.02 \mathrm{~m} / \mathrm{s} ;(\mathrm{e}) 0.08 \mathrm{~m} / \mathrm{s}$

According to the standard PDF card, we found that the XRD patterns in Fig.5(a) and Fig.5(b) are matched with the standard PDF card(No.70-0989), the strongest diffraction peaks are (200) and (111) crystal surface, while the other diffraction peaks are not obvious. The XRD patterns in Fig.5(c) to Fig.5(e) are matched with the standard PDF card(No.65-6491), the diffraction peaks correspond to the crystal surface are (111), (200), (220), (311) and (222) crystal surface, and they are all face-centered cubic structure.

As shown in Fig.5, comparing with the sample electroformed from the bath without hard particles, the difference of the intensity of the diffraction intensity of each crystal plane is decreased in the deposits electroformed by adding hard particles in the bath. The diffraction peak of (200) crystal surface decreases sharply, while the diffraction intensity of (220), (311) and (222) crystal surface is increased by different degrees.

The above analysis shows that the growth of crystallites and their relative speed of growth were affected by the friction of the hard particles. The experimental results show that the friction of hard particles could inhibit the growth of (200) crystal surface, and promote the growth of (220), (311) and (222) crystal surface.

\section{Conclusions}

The nickel deposits were electroformed with hard particles in the bath and their microstructure were examined. The experimental results show that the disturbing and polishing of hard particles in the 
bath could obviously have a role in grain refinement, and when speeding up the velocity of cathode, the polishing effect of hard particles can be strengthened.

It was also found that the friction of hard particles affect the growth of crystallites and their relative speed of growth, which leads to the change of surface diffraction density and orientation index. The grain size was about $100 \mathrm{~nm} \sim 600 \mathrm{~nm}$, while the linear velocities of cathode were between $0.0025 \mathrm{~m} / \mathrm{s}$ to $0.08 \mathrm{~m} / \mathrm{s}$.

\section{Acknowledgement}

The work described in this paper was supported by the Jiangsu Planned Projects for Postdoctoral Research Funds, China (No. 1402032C).

\section{REFERENCES}

[1] HART T, WATSON A, Electroforming,J. Metal Finishing, 2000, 98(1): 388-399

[2] SRIVASTAVA M, SEL VI V E, GRIPS V K W, et al, Corrosion resistance and mircostrure of electrodeposited nickel-cobalt alloy coatings,J. Surface \& Coatings Technology, 2006, 201(6):3051-3060

[3] MCGEOUGH J A, LEU M C, RAJURKAR K P, DE SILVA A K M, LIU Q, Electroforming process and application to micro/macro manufacturing,J. Annals of the CIRP, 2001, 50(2):499-514

[4] Xuelei Li, Zengwei Zhu, Yong Zhang, Dong Zhu, Di Zhu, Experimental research on electroforming of complex parts with thin wall,J. Chinese Journal of Aeronautics, 2010, 31(10): 2068-2074(In Chinese)

[5] Oh Y J, Chung S H, Lee M S, Optimization of thickness uniformity in electrodeposition onto a patterned substrate, J. Materials Transactions, 2004, 45(10): 3005- 3010

[6] Lee J M , Hachman J T, Kelly J J, Improvement of currentd istribution uniformity on substrates for microelectro-mechanical systems,J. Journal of Microlithography, Microfabri- cation, and Microsystems, 2004, 3(1): 146-151

[7] Jiangang Qian, Pengrui Li, Haiting Li, Influence of bath composition on microstructure and mechanical properties of electroformed nickel,J. Journal of Aeronautical Materials, 2014, 34 (2): 11-16(In Chinese)

[8] SILAIMANI S M, JOHN S, Review on recent advances in electroforming during the last decade,J. Bulletin of Electrochemistry, 2001, 17 (12): 553-560

[9] DI BARI G A,. Nickel plating,J. Plating Surf. Finish, 2004, 91(8): 23 26

[10] Di Zhu, Zengwei Zhu, Ningsong Qu, Abrasive polishing assisted nickel electroforming process,J. CIRP Annals-Manufacturing Technology, 2006, 55 (1): 193-196 